\title{
Ocho notas críticas sobre políticas de protección a niños y adolescentes en América Latina ${ }^{1}$
}

\section{Eight critical notes on policies to protect Children and Adolescents in Latin America.}

Aceptación: 15 de marzo de 2010.

Mónica De Martino, Dr. Ph. ${ }^{2}$

Aprobación: 5 de junio de 2010.

\section{RESUMEN}

La ponencia intenta colocar ocho observaciones críticas a las actuales políticas de protección a la infancia y la adolescencia en la región. Cuatro de ellas, en nuestra opinión, derivan de la forma como fue abordado el campo de la infancia y la adolescencia, desde una perspectiva histórica, tanto desde la política como de la academia. En otras palabras, son notas intrínsecas a la relación infancia, pobreza y Estado. Las cuatro restantes se vinculan al actual sistema de protecciones sociales vigente en la región, que apunta a regular la pobreza bajo el signo de políticas sociales y políticas punitivas. La infancia, como "puerta de entrada" a la familia y sus secretos, habilitó históricamente, a partir de las políticas dirigidas a ella, la gestión social y política de la pobreza y de la población en general. Estas últimas cuatro notas críticas son intrínsecas a las actuales formas de ejercicio del poder gubernamental y a la concepción de qué debe ser protegido y cómo. Obviamente, los ocho comentarios se desglosan de esta manera a los meros efectos de su exposición.

Palabras clave: Representaciones sociales sobre infancia, políticas sociales, políticas penales, gestión de la pobreza.

\begin{abstract}
The paper attempts to place eight critical observations on the current policy of protecting children and adolescents in the region. Four of them, in our view, derived from the way it was addressed the field of childhood and adolescence, from a historical perspective, both in politics and academia. In other words, they are intrinsic to the relationship notes childhood, poverty and state. The remaining four are linked to the current social protection system in force in the region, aiming to regulate poverty under the banner of social policies and punitive policies. Childhood as a "gateway" to the family and its secrets, historically enabled, from policies aimed at her, social and political management of poverty and population in general. These last four critical notes are intrinsic to the current forms of exercise of governmental power and the conception of what should be protected and how. Obviously, the eight comments are broken in this way to mere exposure effects.
\end{abstract}

Key words: Social representations of children, social policies, criminal policies, management of poverty.

Versión sintética de la ponencia presentada en el Primer Encuentro Nacional Interdisciplinario de Derechos Humanos y Sociedad Civil y III Seminario Internacional de Derechos Humanos, Violencia y Pobreza. Montevideo, 24-26 de noviembre 2010. UDELAR - FCS - Fac. de Derechos, Servicio Paz y Justicia, Cátedra Unesco.

2 Prof. Agregada en Régimen de Dedicación Total. Docente e Investigadora del Departamento de Trabajo Social de la Facultad de Ciencias Sociales y del Centro Interdisciplinario Infancia y Pobreza - EI - UDELAR - Montevideo. monicad@ fcs.edu.uy 


\section{Introducción}

Desde hace unas décadas las políticas de protección a niños y adolescentes han reformulado su discurso a lo largo y ancho del continente y es evidente también que infancia y adolescencia han ingresado a las agendas políticas de la región de la mano de la Convención Internacional de Derechos del Niño, CIDN.

Podríamos resumir groseramente que la década de los ochenta, caracterizada por la recuperación de la vida democrática en algunos países de la región, se caracterizó por una nueva impronta en los sistemas de protección a niños, niñas y adolescentes - de aquí en más NNA- basada en lo que ha sido dado en llamar Doctrina de la Protección Integral.

Obviamente, esta nueva perspectiva se encuentra asociada a nuevas concepciones de la vida democrática y a una nueva comprensión de la relación de la infancia con la democracia (Baratta, 1995). Pero tampoco puede ser analizada sin tener en cuenta las modificaciones sustanciales percibidas en el patrón de protección social general.

Esto es, más allá de nuevos direccionamientos plausibles, contradictoriamente las políticas de protección a la infancia y a la adolescencia se encuentran atravesadas por dos líneas problemáticas. Por un lado, por aquellos dilemas propios de su historia y del ideario político que caracterizó la comprensión y tratamiento de la niñez y adolescencia. En segundo lugar, por las reglas que competen al nuevo patrón de protección social instalado en la región a partir de los años ochenta, pero con mayor énfasis a partir de los noventa.

Las limitaciones provenientes de ambos campos problemáticos hacen que no avizoremos un futuro promisorio para nuestros NNA, a corto y mediano plazo, en nuestro continente, más allá de los avances constatados. Si bien exponemos tales limitaciones por separado, para los efectos del análisis, se encuentran vinculadas por su propio devenir histórico.
Cuatro notas críticas que surgen de la historia específica del campo de la infancia y adolescencia

A continuación enumeramos someramente los dilemas que emergen de la primera línea problemática señalada ut supra y que deberían ser superados en nuevas modalidades de políticas de protección.

1. Las representaciones y prescripciones sobre la infancia y la adolescencia no tienen un estatuto ontológico ni epistemológi$\mathrm{co}$, sino fundamentalmente político. Esto las transforma en objetos alienados de estudio $e$ intervención sociopolítica, que son pensados, hablados y construidos siempre desde fuera de ellas. La infancia y la adolescencia no hablan.

No es arriesgado decir que la historia de la infancia es también la historia de la retirada gradual de la cuestión social infantil del universo de las cuestiones de Estado. Parecería que las cuestiones vinculadas a la "minoridad" han quedado residualmente apegadas a la actuación estatal. Tal vez, en nuestro país, la Estrategia Nacional para la Infancia y Adolescencia haya sido uno de los primeros puntos en contradecir esta tendencia.

El niño o la niña que se torna sujeto de un proceso, ya sea de naturaleza jurídica, médica, social y, por ende, política, se torna también en objeto de estudio y debate. Y es presentada con las prácticas narrativas y discursivas ya sean estas del médico, maestro, jurista, psicólogo, trabajador social. Su comportamiento, pero especialmente su futuro, su futura trayectoria vital, se torna subordinado a las consideraciones expresadas por esos saberes expertos. Tales saberes, que se plasman en diversas fuentes, operan con -pero también sobre- imágenes de la infancia que asumen la forma fantasmagórica del ser social representado en el argumento científico.

En el siglo XIX, una cartografía de los saberes nos indicaría que la medicina, la psiquiatría, la pedagogía, fueron aquellos saberes que más representaciones sobre la infancia produjeron. Lo normal y lo patológico; barbarie y civilización, higiene y salud, 
educación y salvajismo, son otras tantas concepciones que conllevan estos saberes. Junto a puntualizaciones $\mathrm{e}$ indicaciones sobre educación, atención a la salud, "correctivos" sociales, tales saberes también plasman expresiones sobre la infancia, sombría o alegre, limpia o impura (Barrán, 1999).

La infancia, como campo de conocimiento, se presenta entonces y desde entonces como un entramado de saberes, donde las fronteras entre tales conocimientos científicos así como entre estos y las prescripciones sobre la familia y la infancia, se tornan difusas. El tema infancia, entonces, aparece en el horizonte del conocimiento en situación de subalternidad.

Como decíamos, si las representaciones sobre la infancia también estuvieron unidas tanto a prescripciones sobre la familia y la propia infancia como a prácticas taxonómicas de patologías médicas, sociales, legales, etc., la infancia y su atención, en algún momento, se transformó en amparo al "menor". En conjunto, tales ciencias fueron favoreciendo que la infancia haya sido lo que dijeron de ella al mismo tiempo que se van construyendo campos a partir de los cuales se negocian nuevos conceptos y nuevos modos de ser de la infancia (Lajolo, 2009:232).

En cuanto objeto de estudio, la infancia es siempre un otro en relación a aquel que la nombra y la estudia. Las palabras infante, infancia y demás sinónimos, en su origen latino y en las lenguas de ahí derivadas, recubren un campo semántico estrechamente ligado a la idea de ausencia de palabra. Esta noción de infancia, como cualidad o estado de infante, esto es, de aquel que no habla, se construye a partir de los prefijos y radicales lingüísticos que componen la palabra: in: prefijo que indica negación; fante: participio presente del verbo latino fari que significa hablar, decir (Lajolo, 2009:229).

Así, por no hablar, la infancia no se habla y, no hablándose, no ocupa la primera persona en los discursos que se ocupan de ella. $Y$, por no ocupar esta primera persona, esto es, por no decir yo, por jamás asumir el lugar de sujeto de discurso, es, consecuentemente, por consistir siempre un él/ella en los discursos ajenos, la infancia siempre es definida de afuera (Lajolo, 2009:230).

Las dificultades para construir la infancia como campo de conocimiento interdisciplinario también están a la hora del día actualmente:

...cuando se les estudia, se ha enclaustrado sus vidas y experiencias en unos pocos subcampos sociológicos - la familia, la educación, la socialización- y son pocos los estudiosos de la organización social, el trabajo, la sociología política y urbana o la estratificación que prestan alguna atención a la existencia de los niños o la cualidad de la infancia. La teoría sociológica muestra un particular adultocentrismo, lo cual la lleva a considerar a los niños solo desde la perspectiva de la reproducción del orden social (Neustadter apud Rodríguez, 2000).

La alienación sufrida por la infancia por las tendencias señaladas arriba, no resta fuerza a las categorías y definiciones por las cuales se habla de ella. La cuestión no es ontológica ni epistemológica: infancia, como negro, mujer, pobre, son categorías que se recrean en el espacio social en que son establecidas, negociadas, desestabilizadas, reconstruidas (Lajolo, 2009).

Si la Convención de los Derechos del Niño fue un momento paradigmático en el campo de la infancia y la familia, también es cierto que surge desde el mundo adulto y con una mirada adultocéntrica. Infancia y adolescencia no han hablado, nada han dicho para la formulación de sus intereses y su traducción en derechos. Tampoco hablan a la hora de producir conocimiento sobre ellas mismas. Por algo el señalado déficit de participación o de brindar opinión. No estamos hablando aquí de una infancia o adolescencia excluida socialmente sino excluida de los circuitos de producción de saberes sobre ellas mismas, lo que resulta altamente paradójico en este recinto universitario.

Políticamente esto tiene como correlato una modificación en términos de cómo ha sido entendida la relación democracia-infancia (Baratta, 1998). Sabemos que la lucha por los derechos de NNA no ha sido una lucha propia sino que ha quedado y queda dependiente 
del discurso y del actuar de los adultos. Algo también paradójico si pensamos el poder de los adultos sobre el mundo infantil y que es a ellos que se dirige el pedido de igualdad, libertad, respeto, etc. En otras palabras, si los niños son buenos para la democracia y la democracia se mide por el reconocimiento a la infancia y adolescencia (Baratta, 1998), podríamos agregar que la democracia, entendida en los niveles social e institucional indicados por el autor, solo se generará para la infancia y adolescencia cuando haya comenzado a medirse con la cuestión infantil como una cuestión interna, no más como una cuestión meramente externa (Baratta, 1998:40).

Si esto hace a un horizonte ético-político compartido, consensuado, debemos reconocer que en nuestro país y en la región, más allá de avances, aún permanece ese carácter extrínseco de la niñez y adolescencia respecto a las políticas de protección dirigidas a ellas mismas y a la propia democracia.

2. Las políticas sociales de infancia y familia en América Latina y Europa siempre han oscilado entre la delicadeza y la atrocidad colocando especial énfasis en la niñez y adolescencia pobre. Este aspecto que políticamente adquiere un carácter genéticoestructural no se ha visto modificado.

Esto lo ha señalado Geremek en su libro La piedad y la horca. Historia de la miseria y de la caridad en Europa. Más allá de ciertos matices, especialmente en lo que respecta a los dispositivos religiosos que generaron miradas diferentes sobre la pobreza, creemos que sus tesis pueden ser aplicadas a América Latina.

Junto a la caridad -de base cristianay las dádivas y limosnas, atravesadas por diversos sentimientos, a fines del siglo XIX, la prisión comienza a ser tratada como pena e incluso como base de todo el sistema penal. Michel Foucault, en Vigilar y Castigar, ha demostrado la importancia que tuvo esta mutación en la tecnología del poder y en el concepto de la pena y de la expiación en el seno de la conciencia social (Geremek, 2009:224).

Antes de que la prisión llegase a ser el medio para el castigo de los delincuentes, ya había sido utilizada como instrumento de la política de salud en el siglo XVIII bajo su forma hospitalaria/asilar para el tratamiento de los enfermos (Foucault, 1991a). Serán los apestados, luego los leprosos, posteriormente los locos y mendigos, para por último instalarse la prisión para los infractores, pero como siempre, para los infractores pobres. Todo ello acompañado por la conciencia de un peligro social.

La creación ya en el siglo XVIII de workhouses indicó esta alternancia entre castigo y educación de los pobres a través del trabajo, con relación a la reforma de la caridad que se produce en ese siglo. Vives, Moro, Modrevius serán sus ideólogos. Nada más lejos de la utopía humanista que estas casas de trabajo coactivo y correctivo, los hospitales penitenciarios, los reformatorios que brindaban mano de obra a bajo precio o directamente gratuita (Geremek, 2009). Hombres, mujeres, niños, pero en especial los jóvenes delincuentes fueron quienes las poblaron.

El nacimiento de la sociedad contemporánea, la primitiva acumulación del capital estuvieron acompañados por estos procesos y estos sentimientos encontrados, como lo demuestra Geremek (2009) en el texto en que nos basamos. Actualmente, se hace visible lo que tan bien expresa Morás (2009:153) al analizar el sentimiento de inseguridad ciudadana con relación a la cultura juvenil en general y en su expresión delictiva: “... se asiste a una especie de 'infantofobia' que parece señalar una desresponsabilización de la sociedad sobre el tema y ser a su vez producto de los desconciertos operados por la 'fragilización' de los roles adultos".

Según el autor (2009), el proceso civilizatorio analizado por Elías aparece como incompleto o perversamente invertido. Pero si lo analizamos desde la perspectiva de esa oscilación entre piedades y horcas, no existen novedades en el mundo de la infancia y la adolescencia. Tal vez, por el contrario, la novedad sea esa "infantofobia" acompañada por la imputación de discernimiento adulto a quienes aún no lo son legalmente y esa suerte de desresponsabilización de la sociedad como indicadores de un proceso civilizatorio perverso. 
También podríamos leer esta dilemática relación entre Estado-familia e infancia desde otra perspectiva. La piedad y la horca -metafóricamente hablando- se encuentran en instituciones que ya no cuentan con posibilidades objetivas ni subjetivas de producir lo que la infancia necesita o, incluso, de acompañar adecuadamente el proceso de producir infancias. Es lo que los autores Corea y Lewkovicz (1999) han denominado "destitución de la infancia", que puede entenderse como el agotamiento de las instituciones que producen niñez o infancia o su incapacidad de hacerlo en tiempos modernos, refiriéndose especialmente a la familia y la escuela, ambas instituciones "sentenciadas" por déficits supuestamente objetivos en el proceso de socialización. La infancia destituida es una infancia anulada, sentenciada, a la que no se le permite ser. La pena capital ha recaído sobre ella, metafóricamente hablando.

Pero, como se desprende de la obra de Corea y Lewkovicz (1999), la infancia destituida, o, para nosotros, la infancia sentenciada, siempre es y ha sido la minoridad, o, los que Morás (1992) denominó, Hijos del Estado. Nos remitimos a lo dicho en la introducción: los niños en peligro o peligrosos, los hijos de la clase trabajadora, los pequeños mendigos, los pequeños rateros, los hijos abandonados de la masa inmigrante o de la avergonzada burguesía, los díscolos, los hijos de la pobreza, aquellos a quienes les fue "destituida" la infancia, han sido históricamente la población objetivo tanto de las políticas de amparo como de protección, represión y control. Es un hecho histórico y ampliamente documentado.

\section{Históricamente en América Latina} la familia se basó más en el parentesco y la familia alargada que en el matrimonio (algo típicamente europeo). Las políticas sociales de infancia y familia no tuvieron en cuenta ello. Sobre la familia, agente fundamental en las políticas de protección a la infancia y la adolescencia, primó el pensamiento parsoniano cristalizado.

Según lo consigna la bibliografía existente y consultada al respecto, en tiempos de la colonización y conquista, se caracterizó por el surgimiento de nacimientos ilegítimos, frutos de amores entre colonizadores y mujeres indígenas. Como ya sabemos, durante este período histórico, los españoles y portugueses eligieron esposas y amantes indígenas o negras, dando lugar a ese fenómeno nuevo que fue el mestizaje. Culturalmente este proceso es fundamental para entendernos como América Latina. Pero desde un punto de vista axiológico, en términos de sociología de la familia, este proceso colocó valores contradictorios: matrimonio versus concubinato o poligamia, en un mismo plano, a la hora de elegir la forma familiar, colocando como algo recurrente la ilegitimidad

Pensar la familia latinoamericana desde sus orígenes implica reconocer las distintas atribuciones imputadas al parentesco, tanto consanguíneo como político, que confluyeron en formas familiares a veces alejadas del matrimonio católico asociado a los conquistadores. Pero también formas familiares a veces alejadas también de las propias culturas.

A diferencia de la familia moderna europea construida sobre el matrimonio (aun con la existencia de divorcio entre los protestantes) y un esquema de sanciones a los amores ilícitos, las uniones consensuales y las relaciones sexuales fuera del matrimonio, la experiencia local impone notables variaciones a partir de un doble patrón sexual: el matrimonio y la liberalidad de las relaciones sexuales. Así las parejas en unión consensual se comportaban como un matrimonio "normal" formando parte de familias extensas, múltiples y compuestas -características en tiempos de la descolonización- que incluían sirvientes, huérfanos, personas con o sin relación laboral con el jefe, etc. Si bien los actores se reconocían católicos no sentían urgencias en cumplir con los mandatos religiosos. Con la llegada al país de los inmigrantes extranjeros desde mediados del siglo XIX hasta entrado el siglo XX, sus comportamientos tendieron a una fuerte endogamia en lo que respecta a la elección matrimonial, lo que solo comenzó a cambiar a partir de la tercera generación (Krmpotic, 2009).

Tal vez esto nos permite entender que lo que aseguró la integración étnica de grupos tan diversos en la sociedad receptora no fue el matrimonio sino la educación primaria, 
conformando de esta manera una sociedad caracterizada por el pluralismo cultural (Ariño, 2007). Paradójicamente, puede entenderse que una política claramente destinada a la protección de la infancia fue un factor de integración étnica más que el matrimonio intercultural.

Pero lo que queremos indicar es que históricamente las políticas de protección, desde sus orígenes, apelaron a la familia nuclear, a la familia refugio, a los límites de la alianza y el parentesco cercano, a los límites de lo seguro, si ello es posible. No vislumbraron como posibles copartícipes en la protección de NNA a personas sin vínculo sanguíneo, pero fundamentales para la vida de aquellos. Los parentescos lejanos también producían - ¿o producen?- cierto desasosiego.

Creemos que hoy tenemos un imperativo político: superar los límites de la alianza y la consanguinidad, y también los límites de los padrones heterosexuales, para entender teóricamente la familia y políticamente incluirla en el diseño de políticas de protección.

4. Las representaciones sobre la infancia y la adolescencia impactan en los cambios de las políticas sociales dirigidas a ellas. Históricamente esta lectura habría sido pertinentemente realizada. En la actualidad tanto la definición de infancia como sus representaciones se han tornado intrínsecamente complejas, lo que podría expresarse en las dificultades encontradas para definir un patrón de protección social y programas y servicios acordes a las nuevas realidades.

La infancia, y más tardíamente la adolescencia, a lo largo de la historia se presenta como una categoría dinámica que ha ido asumiendo diversos significados de acuerdo con los contextos sociopolíticos y culturales a partir de los cuales se la piensa. Nos encontramos, aunque parezca obvio decirlo, frente a una categoría que no es ni natural ni universal (Buckingham, 2002:18; Postman, 1994: XI; Steinberg y Kincheloe, 2002:14; Varela y Alvarez-Uría, 1991:15).

Su significado "está sujeto a un proceso constante de lucha y negociación, tanto en el discurso público (por ejemplo, en los medios de comunicación, en el ámbito académico y en la política social) como en las relaciones interpersonales, entre iguales y en la familia" (Buckingham, 2002:18).

Históricamente, la infancia no fue considerada como una especificidad, poseedora de rasgos propios con maneras particulares de sentir y pensar, sino que fue pensada como una construcción social que en la medida que era definida y delimitada, permitía además su objetivación. Ariés (1986), a partir del análisis de imágenes pictóricas, sostiene que la infancia, en tanto categoría diferente al adulto, tuvo su origen en el siglo XIII y su reafirmación a partir del siglo XVI, cuando el niño comienza a despertar sentimientos de ternura ("mignotage") y es gradualmente alejado de las actividades productivas, educacionales y recreativas que solía compartir con los adultos (Narodowski, 1994:31). Por su lado, Gélis (1992:315) reconoce que recién a finales del siglo XIV aparecen en los medios acomodados de las ciudades algunos indicios de una nueva relación con el niño, por ejemplo, las muestras de afectividad y la preocupación por preservar la vida del niño. Luego, ya en el siglo XVIII surgen nuevas prácticas de crianza que denotan un mayor cuidado por parte de los padres hacia sus hijos, a partir de los consejos propiciados por los médicos de la época. Típico ejemplo: las campañas a favor del amamantamiento materno y las disputas en torno de la figura de las nodrizas (Ariés, 1986; Gélis, 1992). En esta misma línea Varela y Alvarez-Uría (1991:134) señalan que, según los escritos de la época, a mediados del siglo XVIII los niños de las clases altas y medias urbanas adquieren un estatuto especial: dejan de ser considerados como adultos en miniatura para adquirir una especificidad particular, ya que hasta el momento se los distinguía solamente por tener menos fuerza, menos conocimientos y menos experiencia. De esta manera se asume que en dicho período vital se poseen ciertas características diferentes a las del adulto $\mathrm{y}$, por lo tanto, las necesidades y preferencias no son iguales a las de sus mayores.

Lentamente, los niños comienzan a ser percibidos como débiles, vulnerables y dependientes. Para protegerlos, se los aleja de la vida que hasta entonces compartían 
con los adultos, por considerarla peligrosa: se prohíbe la participación de los pequeños en los juegos de azar, en las apuestas de dinero y cada vez se ejerce un mayor control desde la familia, aumentando la diferenciación entre los espacios públicos y los privados (Varela y Alvarez-Uría, 1991:135). Narodowski (1994:32) afirma que, como síntoma de la profunda mutación en la cultura occidental, se fueron modificando las relaciones entre niños y adultos y surgieron nuevos sentimientos como el amor maternal, la protección y la dependencia respecto de sus mayores.

Contraria a la postura de autores como Ariés (1986) o Postman (1994), Pollock (1993) afirma que en el siglo XVI hubo un concepto definido de niñez, que posiblemente se terminó de delinear con el paso del tiempo. Señala que los autores del siglo XVI apreciaban las diferencias entre los niños y adultos y reconocían los campos en los que se distinguían: los primeros pasaban por determinadas etapas de desarrollo perfectamente reconocibles; jugaban, necesitaban disciplina, educación y protección (Pollock, 1993:305). La autora se coloca así en una posición efectivamente distinta a la de Ariés (1986) y Postman (1994), que puede ser caracterizada como una mirada evolucionista/civilizatoria sobre la infancia.

Sin embargo, más allá de estas diferencias, en estas tendencias que podríamos denominar historia de la infancia, los autores consultados $^{3}$ acuerdan en que han existido variaciones en las formas de sentido otorgadas a la niñez. No obstante ello, identifican en el siglo XIX una forma particular de infancia, la cual fue denominada infancia moderna o tradicional, caracterizada por la aparición de nuevos sentimientos de los adultos respecto de los niños, el desarrollo de prácticas específicas para la niñez - como la masificación de la escolarización, que habilitó un espacio exclusivo para niños generando una distinción entre el estatus infantil y el adulto- y el surgimiento de nuevos comportamientos ligados al cuidado de los niños.

En síntesis, a través de las nuevas relaciones familiares y escolares y el auge de los especialistas en la infancia se fue definiendo lo aceptable, deseable y esperable para los niños, pautando así una subjetividad de la infancia "normal", cuyas características pueden resumirse en: inocencia, docilidad, obediencia, heteronomía, desconocimiento y fragilidad $^{4}$.

En este breve recorrido por la historia de la infancia se evidencia cómo los niños a lo largo del tiempo fueron considerados de diferentes maneras y cómo paulatinamente se fue constituyendo la identidad tradicional que se consolidó con la masificación de la escuela. Hoy por hoy, se presentan cambios importantes en tal concepción que llevan a algunos autores a hablar del fin de la infancia. Estos autores sostienen que la noción de infancia tiene márgenes acotados y que, así como se originó en un determinado momento, en la actualidad estaríamos frente al fin de una forma de entender a la infancia y su mundo así como el entramado institucional que la reproduce y/o la protege. Así, por ejemplo, Postman (1994: xii); Steinberg y Kincheloe, (2002:15); Corea y Lewkowicz, (1999:11) se encuentran en esta línea de pensamiento.

De una forma menos radical, Narodowski (1999) acuerda con la idea de la crisis del sentido moderno de infancia pero sostiene que no se trata de un "vacío" de la categoría infantil sino de su reconfiguración hacia dos polos: la infancia desrealizada y la hiperrealizada. Con la primera alude a los niños que no atraviesan la infancia debido a que viven en la calle o a que trabajan desde muy temprana edad y, por lo tanto, aprenden a autoabastecerse para poder sobrevivir de forma similar a los adultos. Con la segunda hace mención a los niños que atraviesan en forma vertiginosa el período infantil de la mano de las nuevas tecnologías y ya no responden al lugar del

Ariés, 1986; Baquero; Narodowski, 1990, 1994; de Mause, 1994; Narodowski, 1994; Pollack, 1993; Postman, 1994; Stone, 1989; Varela y Alvarez-Uría, 1991.

4 Esta caracterización es una síntesis de los rasgos enunciados por: Postman, 1994; Baquero y Narodowski, 1994; Narodowski, 1994, y Corea y Lewkowicz, 1999. 
no saber (Narodowski, 1999:46-57). De esta manera explica el declive de la infancia moderna y, por ende, de la percepción del niño como "obediente, dependiente, susceptible de ser amado" (Narodowski, 1999:47). Obviamente, el autor recoge los tipos ideales construidos por Buckingham (2002) a modo de metáforas, para la construcción de tales categorías.

Para mostrar los contrastes entre la infancia actual y la de otras épocas, Steinberg y Kincheloe (2000:30) marcan la pérdida de la inocencia como un rasgo distintivo de los niños de hoy. Por su lado, Corea y Lewkowicz resaltan un quiebre de la concepción del niño como proyecto de futuro hombre: en la actualidad el niño ya es (1999:12). Además, algunos autores advierten nuevos roles en la infancia como la figura del niño consumidor o la ya mentada figura del niño como sujeto de derechos (Buckingham, 2002; Rabello de Castro 1999, Corea y Lewkowicz, 1999) ${ }^{5}$.

Si las representaciones de la infancia y la adolescencia impactan en la concepción de las formas de protección social a ser brindadas, obviamente, ante esta infancia destituida, desdibujada, en algunos campos en franca ventaja respecto al mundo adulto, las formas de protección social deben ser pensadas de manera creativa. No obstante, pueden percibirse en la actualidad dos tipos de actitud estatal, en función de las problemáticas que atraviesan los destituidos de infancia. Lo que queremos indicar es que si históricamente solo la infancia y la adolescencia pobre fueron objeto de políticas de protección, actualmente esto no ha podido ser superado estrictamente. Aún pensamos en la infancia destituida o desrealizada cuando hablamos de protección social en el campo de la infancia y adolescencia. Aun cuando es por todos conocido que problemáticas que atañen a la niñez y la adolescencia atraviesan clases, razas, sexos y credos.

No toda la infancia y adolescencia son de interés político o, en otras palabras, la infancia y adolescencia concitan diferentes intereses sociopolíticos. Los hijos e hijas de la pobreza ameritan el interés por la seguridad, la corrección de los incorregibles, el disciplinamiento de los indisciplinados, la protección social para poder acceder a contados derechos. La infancia desrealizada amerita intereses políticos encontrados, nuevamente la piedad y la horca. La infancia hiperrealizada concita, entre otros sanos intereses: la promulgación y defensa de sus derechos, la escucha de su opinión. Pero concita otro que creemos de carácter negativo: el transformarla en un conglomerado altamente consumidor y que es constantemente impelido a consumir. Sobre este conglomerado hiperrealizado y harto consumista creemos que no existen políticas claras de protección, si es que partimos de la base que un consumo desenfrenado no significa la materialización de derechos que hacen al colectivo humano.

En pocas y breves palabras, la infancia moderna ha mutado en algo que es nombrado de diversas maneras pero que todas ellas poseen un significado de pérdida, de indefensión, de vidas al límite y sin límites. Ante ello, no alcanza el acervo de políticas con las cuáles se cuenta. Tampoco alcanza con el acervo teórico que las alimenta ni, muchas veces, con la intencionalidad política de las mismas. Lo que se impone es un análisis pormenorizado de los mecanismos de doble regulación a los cuáles están sometidos los pobres, especialmente urbanos. Mecanismos que vinculan políticas sociales y los más diversos grados de las políticas penales desde la judicialización de la vida privada hasta el encierro/castigo (Wacquant, 2010).

Tanto para Buckingham (2002) como para Postman (1994) el papel de la TICs es fundamental para comprender estas transformaciones. Postman, incluso, llega a atribuir el "fin de la infancia"12 al auge de la televisión -surgida en Estados Unidos a partir de 1950-. Se basa en que, al no implicar ningún esfuerzo para la decodificación de sus mensajes, permitió el acceso a todo tipo de información a cualquier edad, borrando las jerarquías adulto-niño implicadas en las barreras de control. Esta postura es discutible ya que, si bien los procesos implicados en la interpretación de contenidos audiovisuales se adquieren más tempranamente que los necesarios para la lectura y que no necesitan de una enseñanza sistemática, sí requieren un esfuerzo para la interpretación de los mensajes. Con lo que se acuerda plenamente es que la televisión puso a disposición de todos todo y todo el tiempo, y generó una horizontalización en el acceso a la información favoreciendo quiebres en la asimetría tradicional entre los niños y los adultos. 
Cuatro notas críticas que surgen de las actuales formas de gestión de la pobreza

\section{La minoridad continúa siendo asunto} de gobierno pero no estrictamente de acción estatal. La individualización de los problemas sociales, el complejo entramado de actores sociales que hacen a los servicios destinados a infancia y adolescencia, nos permitirían hablar de una relación entre la infancia/adolescencia y el Estado ya no lineal sino mucho más sinuosa que la que caracterizó el Estado Social, más allá de nuestra matriz estadocéntrica.

Creemos que en el período analizado, más que de disciplinamiento, nos enfrentamos a un nuevo Estado y a nuevas formas de ejercicio del poder. El punto de inflexión que se observa en la obra de Foucault, a partir de La Historia de la Sexualidad. Volumen I La Voluntad de Saber y más explícitamente en su conferencia sobre La gubernamentalidad, fueron los insumos que nos permitieron ir más allá de nuestro objeto de investigación. En estos textos el autor abandona la hipótesis Nietzsche, para el análisis del poder, en el entendido que la guerra ya no posee capacidad heurística para el análisis del poder en sociedades modernas y complejas.

La gubernamentalidad puede entenderse como una determinada economía del poder - una forma de gobierno definida por la masa de la población, su volumen, su densidad-que apunta a las diversas prácticas, destinadas a controlar individuos y colectivos y a generar las formas de autogobierno que se pretenden alcanzar (Foucault, 1992b: 292-293).

El autor coloca de esta manera la problemática del gobierno y del Estado. Foucault modifica, así, su anterior noción de poder, lo que le permite analizar las relaciones entre cómo el ejercicio del poder gubernamental estatal logra fomentar, por un lado, el autogobierno o gobierno de sí $y$, por otro, la conducción de la conducta de los otros, o en otras palabras, el gobierno de una nación.

Este nuevo arte de gobierno no consiste en aplicar medidas represivas sino en lograr que tanto la disciplina como el control de sí sean interiorizados. En el orden social así analizado no solo se fuerza al individuo, a los cuerpos y a las cosas, sino que estos juegan, paralelamente, un papel activo. Las técnicas de dominio gubernamental no se basan en la regulación exterior de sujetos autónomos y libres sino en la regulación de las relaciones mediante las cuales estos se constituyen a sí mismos como tales, como sujetos, en el sentido estrictamente foucaultiano (Foucault, 1992b).

Si, como ya señalamos, en el primer volumen de Historia de la Sexualidad, Foucault hablaba de las tecnologías de poder sobre la vida, relacionando el disciplinamiento de los cuerpos concretos con el del cuerpo social, en las clases magistrales que dictó en 1978 y 1979 fue aún más allá. Desplegó con mayor énfasis su microfísica del poder hasta llegar a estructuras y procesos macroscópicos (Lemke, 2001) En estas clases analizó las transformaciones de las tecnologías del poder y su centralización en el Estado moderno, en un proceso que dio en llamar gubernamentalización del Estado (Foucault, 2006) entendiendo por tal el entrelazamiento estructural del gobierno de una nación con las técnicas de gobierno de sí (Lemke, 2001).

A este Estado gubernamentalizado, asociado por algunos autores al modelo neoliberal y que fomenta, como ya hemos visto, el autocontrol y la capacidad individual o familiar de administrar riesgos bajo un discurso basado en derechos, le corresponde una específica forma de ejercicio del poder. "El ejercicio del poder consiste en guiar las posibilidades de conducta y disponerlas con el propósito de obtener posibles resultados. Básicamente el poder es menos una confrontación entre dos adversarios, o el vínculo de uno respecto del otro, que una cuestión de gobierno.

(...) El "gobierno" no se refiere solo a estructuras políticas o a la dirección de los estados; más bien designa la forma en que podría dirigirse la conducta de los individuos o de los grupos (...) Gobernar, en este sentido, es estructurar un campo posible de acción de los otros (Foucault, 2001: 253-254).

Ya hemos visto cómo familia y comunidad se tornan en elementos centrales para 
guiar conductas. 0 , al menos, hemos visto la intencionalidad de las políticas y programas analizados al respecto. Pero esta forma de ejercicio del poder tiene un fundamento:

\section{(...) se trataría de una especie de desin-} versión. (...) Actualmente el Estado se halla ante una situación tal que no puede ya permitirse ni económica ni socialmente el lujo de ejercer un poder omnipresente, puntilloso y costoso. Está obligado a economizar su propio ejercicio del poder. Y esta economización va a traducirse, justamente, en ese cambio del estilo y de la forma del orden interior (Foucault apud Marinis, 1999: 79).

La economización del ejercicio del propio poder se relaciona, paralelamente, con la complejización del Estado, proceso que como ya vimos, Foucault dio en llamar gubernamentalización del mismo. Se recodifica su función y se replantean las de sus instituciones anexas y complementarias. Pero también se erigen nuevos espacios sociales de intervención y surgen nuevos agentes que desafían la clásica lógica dicotómica Estado Sociedad Civil. En otras palabras, lo que está en juego, teóricamente, es el esquema analítico establecido hace más de dos siglos por la filosofía política en el marco de la crítica liberal a la razón de Estado absolutista. Siguiendo a Foucault estrictamente, lo que está en juego es encontrar respuesta a preguntas tales como: ¿hasta qué punto gobernar?, ¿de qué manera economizar el ejercicio del poder estatal? (Foucault, 2006). Así, organismos estatales y supraestatales, las ONG, organismos internacionales financieros o humanitarios, agencias de consultoría, think tanks, conglomerados de medios de comunicación, lobbies, partidos políticos, organizaciones sociales y comunitarias de diverso tipo (empresariales, sindicales, profesionales, vecinales, de base étnica o de género, etc.) pasan a constituir una densa red en cuyo marco se planifican, diseñan, ejecutan y evalúan políticas, planes y programas de gobierno (De Marinis, 1999).

Retomando a Foucault y a los autores reunidos bajo el rótulo de gubernamentality stadies (Dean, 1999; Gordon, 1999; Lemke, 2001; Rose\&Miller, 1992) se verifica, como medio y como efecto de esta nueva situación, una creciente economía de los medios de go- bierno que utiliza el Estado. Esquemáticamente: el Estado economiza, racionaliza, optimiza cada vez más sus energías, aprovechándose, sirviéndose de y apelando a la energía de los gobernados mismos, para gobernarlos mejor. Para ello también apela a las ONG, financiamientos externos (BID - BM), agentes omnipresentes en el período analizado.

Se procura la economización más efectiva posible de los medios de gobierno, y se trata entonces de gobernar contando con la mayor cantidad posible de la energía que, para su propio gobierno, aporten los gobernados y otras entidades que clásicamente no han sido entendidas como parte de la estructura estatal. En suma, un Estado "adelgazado" (O'Malley, 1991,1996) pero presente, que imbricado con comunidades activas e individuos y familias (Bauman, 2003) conforma la nueva trama de la gubernamentalidad neoliberal. Basta recordar los porcentajes de niños atendidos en el Instituto del Niño y del Adolescente del Uruguay - INAU, a través de convenios y en la propia institución, históricamente invertidos. En el año 2008 aproximadamente el $80 \%$ de los NNA eran atendidos bajo formas convenidas.

Esta economización no implica simplemente, la lisa y llana expansión de la economía sobre la política, sobre el Estado o sobre la sociedad. Tampoco es una suerte de ocupación de la sociedad por parte del mercado, en una suerte de juego de suma cero según el cual a cada avance del mercado le seguiría necesariamente un retroceso del Estado. Si esto fuera así, habría todavía un cierto margen de actuación para una intervención desde la política para recuperar el terreno perdido, para poner límites a los desbordes del capitalismo. De este modo, economización no significa simplemente retirada, retroceso o desaparición del Estado. Tal como lo formula comprimidamente Lemke (2001: 198):

Lo que se puede observar no es una disminución de la soberanía estatal o de sus capacidades de planificación, sino un desplazamiento desde formas formales hacia formas informales de gobierno. Esto comprende la relocalización de modelos de acción definidos estatalmente hacia niveles supraestatales, así como el establecimiento de nuevas 
formas de subpolítica, que al mismo tiempo operan "por debajo" de aquello que tradicionalmente constituyó lo político.

Aunque podría sostenerse que el Estado transfirió y delegó algunas de sus tradicionales funciones y responsabilidades, eso no significa de ninguna manera afirmar que haya disminuido su centralidad como espacio de decisiones, como usina central de gubernamentalidad. Como bien sostiene Garland (1997: 175), el Estado sigue siendo un nodal point de las prácticas de gobierno. Aunque, también debe admitirse, ha dejado de ser la única fuente de actividad gubernamental. Asistimos entonces a una autonomización del Estado de otras numerosas entidades de gobierno, con las que, sin embargo, permanece vinculado a través de una compleja cadena de relaciones, responsabilidades, empowerment de diferentes sectores y agencias, distantes del centro estatal. Mecanismos indirectos por los cuales se produce un nuevo tipo de alineación de la conducta personal, social y económica con objetivos sociopolíticos de más amplio espectro.

Estos procesos pueden observarse claramente en las últimas décadas: tercerización de servicios otorgando un papel relevante a ONGs, el surgimiento de la filantropía empresarial -muchas veces vinculada a problemáticas asociadas al mundo de la infancia y de la familia- vínculos cada vez más estrechos con los organismos financieros internacionales, transversalidad en el diseño de políticas y programas dentro de la propia estructura estatal.

2. ¿Derechos del Niño/a y Adolescente o mera retórica? En torno de esta pregunta se entreteje uno de los dilemas que se han instalado en la región con mayor vigor. Hijo del matrimonio malavenido entre los propios avances en materia legislativa y sociopolítica respecto a la infancia y adolescencia y la pobreza de las propuestas estrictamente políticas.

Es obvio señalar el impacto que tuvo en las décadas analizadas la Convención Internacional de los Derechos del Niño, CIDN, y de nuestro Nuevo Código de la Niñez, promulgado en septiembre de 2004. Del mismo modo los avances en materia legislativa, como la denominada Ley de Violencia Doméstica, así como los avances objetivos en términos de derechos de la mujer. Pero, ¿qué papel juegan, en verdad, en término de políticas sociales e intervenciones familiares? Creemos que el problema es más profundo y trasciende el campo de la infancia y la adolescencia. Los derechos del hombre, los derechos humanos, los de los niños, niñas y adolescentes, los de las mujeres, minorías étnicas, sexuales, etc. parecerían ser hoy una suerte de panacea frente a lo que nosotros hemos dado en llamar la reproducción ampliada del dolor en nuestras sociedades actuales. Las dosis de violencia, material y simbólica, que se reflejan en los niveles de pobreza de la población beneficiaria de los servicios analizados, en las problemáticas que atraviesan, y en el tipo de respuesta institucional que reciben con relación a la magnitud de sus necesidades, más allá de buenas intenciones, parecerían ser activamente aceptadas, pasivamente contempladas por la sociedad en su conjunto. A ello llama Zizek (2005) la suspensión política de la ética y ante ella, el discurso basado en derechos parecería ser un contrapeso. No obstante, ese contrapeso aparece como despolitizado, en palabras de Brown (2004: 453):

... se presenta como algo antipolítico, una pura defensa de los inocentes y desposeídos contra el poder, una pura defensa del individuo contra las inmensas y potencialmente crueles o despóticas maquinarias de la cultura, el Estado, la guerra, el conflicto étnico, el tribalismo, el partriarcado y otras acciones $o$ decisiones del poder colectivo contra lo individuos. Pero la pregunta que plantea la autora es interesante: “Qué clase de politización ponen en marcha (aquellos que intervienen a favor de los derechos humanos) contra los poderes a los que se oponen? ¿Sostienen una formulación diferente de la justicia o se mantienen contrarios a los proyectos de justicia colectiva?" (Brown, 2004: 454).

Jaques Rancière (2004: 305) proporciona otra mirada sobre la antinomia entre derechos humanos y la politización de los derechos civiles y políticos. La antinomia no es entre la universalidad de los derechos humanos y una esfera política específica, la brecha 
más importante es la que "separa a la totalidad de la comunidad en sí misma". Podríamos plantear la siguiente paradoja presente en nuestros países: muchas veces los derechos humanos se reducen al ámbito de aquellos que precisamente ya no tiene derechos, son tratados como inhumanos o infrahumanos, pero los derechos son, como ya los sabemos, normas jurídicas de carácter universal y abstracto.

Esta paradoja se desliza a umbrales difíciles de superar pero que debemos visualizar. Una vez concebidos los derechos humanos sin hacer referencia a los derechos universales y metapolíticos, perdemos como referencia a la propia política, lo que constituye una verdadera ingenuidad o perversidad. Reducimos la política a un mero juego de negociación de intereses particulares, ya sea en el ámbito cerrado de la política, ya sea entre los que ya nada tienen y el Estado, vía programas y políticas sociales. Esta sana convocatoria de los derechos humanos, en sentido amplio, también debe ser analizada como un componente sustantivo de las políticas sociales para la infancia y la adolescencia que caracterizan las últimas décadas:

...cuando no son de utilidad, hacemos lo mismo que las personas caritativas con sus ropas viejas. Se las damos a los pobres. Aquellos derechos que parecen ser inútiles en su lugar son enviados al extranjero junto a remedios y ropas, con destino a gente privada de remedios, ropas y derechos. Es de este modo, como resultado de este proceso, que los derechos se convierten en los derechos de aquellos que no tienen derechos, los derechos de seres humanos desnudos sujetos a una represión inhumana y a condiciones inhumanas de existencia. Se convierten en derechos humanitarios, los derechos de aquellos que no pueden ejercerlos, las víctimas de la negación absoluta de derechos. Por todo esto no son vacíos. Los nombres y lugares políticos nunca se vuelven meramente vacíos. El vacío es llenado por algo o por alguien. (...) El derecho a la intervención humanitaria puede ser descripto como una especie de "retorno al remitente": los derechos no usados que han sido enviados a los despojados de ellos son devueltos al remitente" (Rancière, 2004: 307-309).
Las construcciones discursivas y prácticas sobre los derechos enfatizan especialmente aquellos vinculados a los niños y adolescentes, no así los derechos de las familias, reconociendo, en algunas instancias, que algunos dispositivos institucionales expulsan a la familia biológica, hecho históricamente constatado pero que aún mantiene vigencia. Sin embargo, la ausencia de una reflexión sobre derechos que supere la mera doctrina y alcance los sentidos de la justicia es un debe en el período (De Martino, 1998).

3. Actualmente parecería que la tendencia a la individualización de los problemas sociales, a través del enfoque de riesgo social, nos permite percibir la utilidad de la infancia para la gestión poblacional, papel que cumplió en otras etapas civilizatorias.

La implementación de políticas sociales focalizadas, en tanto prácticas políticas, tiene precisamente una de sus manifestaciones en la progresiva adopción del enfoque de riesgo -Risk Approach- como forma de implementar la selección de servicios y cuidados y también de las poblaciones objetivo de las mismas. No es necesario aclarar que el concepto de riesgo social se encuentra presente no solamente en muchas políticas y programas destinados a la infancia y la familia, sino también en la legislación del periodo respecto a niñez y adolescencia.

Cabe resaltar que es el propio Beck (1998) el que resalta que el concepto de "riesgo" no tiene un estatuto ontológico sino que es producto de la razón del analista, del científico y por lo tanto, agrega Douglas (1990), altamente manipulable políticamente. Entonces, ¿qué significa "población en riesgo" o "familia en riesgo"? Lo que los diseñadores e implementadores de las políticas sociales consideren en un contexto sociohistórico específico y ello no implica que el carácter adjetivo de "en riesgo" pueda ser imputado ontológicamente a los sujetos involucrados. Pero lo que sí bien señala y demuestra Mitjavila (1999) es que el enfoque de riesgo se ha transformado tanto en un dispositivo biopolítico como en una nueva tecnología biopolítica para la gestión tecnocrática e individualización de los riesgos. 
El planteo de Mitjavila (1999) nos da pie para indicar otra expresión de nuevas formas de ejercicio del poder y las racionalidades en las que se basan. Nos referimos a una sutil y constante individualización de los problemas sociales.

"Las grandes transformaciones en juego podrían resumirse diciendo (...), que la flexible figura del mercado transnacional reemplaza a la rígida planificación estatal de la economía nacional; las viejas responsabilidades sociales welfaristas se trastrocan $y$ se recodifican en formas mercantilizadas, crecientemente desocializadas, de previsión individual y familiar; simultáneamente, se inyecta en los sujetos una conducta empresarial que debe reemplazar la "pasividad" y la "dependencia" propias de una época pasada" (De Marinis, 1999, p. 93).

En tanto las instituciones sociales que organizaban y canalizaban los comportamientos han perdido su fuerza estructurante como marcos colectivos que funcionaban como orientadores de acciones y estructuradores de identidades, en un proceso que podríamos denominar de desintitucionalización, se percibe esta individualización creciente de las problemáticas sociales abordadas por las instituciones que conforman el dominio empírico de la investigación. Así, la desvinculación respecto de los marcos objetivos que estructuraban la existencia de los sujetos se traducen en un imperativo social que obliga al individuo a ser autónomo y responsable. De documentos nacionales e internacionales, cobra fuerza un discurso que apunta a la responsabilidad individual y familiar. Asimismo, tanto la Convención de los Derechos del Niño como nuestro Nuevo Código de la Niñez y Adolescencia aprobado en septiembre de 2004, colocan la responsabilidad de la concreción de los derechos establecidos, tanto en el Estado y la comunidad, como en la familia, aunque las familias vinculadas a las instituciones asistenciales tengan, en su amplia mayoría, sus derechos conculcados, lo que paradójicamente sería responsabilidad estatal. Del mismo modo, documentos de organismos financieros internacionales (BID, BM) colocan énfasis en la necesidad de fomentar estilos de vida saludables. Para lograr fomentar tales estilos de vida se observan: las orientaciones profesionales en torno de la modificación de los hábitos alimentarios, patrones de consumos, elección y fomento de un determinado recorrido educacional para los hijos, el adiestramiento en técnicas de estimulación temprana, el fomento de la participación en actividades diversas, etc. Estos lineamientos de las prácticas profesionales podrían entenderse como componentes de las tecnologías del yo que se pretende los beneficiarios asuman. En palabras del propio Foucault (1995, p. 98):

"Las tecnologías del yo permiten a los individuos efectuar por cuenta propia o con la ayuda de otros, cierto número de operaciones sobre su cuerpo y su alma, pensamientos, conducta o cualquier forma de ser, obteniendo así una transformación de sí mismos con el fin de alcanzar cierto estado de felicidad, pureza, sabiduría o inmortalidad".

Con relación a esto, De Marinis (1999) habla de una racionalidad que apunta a la creación de una nueva subjetividad, que denomina homo prudens, haciendo referencia al imperativo de que cada individuo y familia sea capaz de administrar sus propios riesgos. En ese sentido y teniendo como telón de fondo las transformaciones de las formas de intervención sociopolítica, importa la observación de Castel (1986: 143), quien al analizar un dispositivo de asistencia francés, señala que no es casual que la infancia se haya constituido como preocupación prioritaria porque:

“(...) con la voluntad de constituir un banco completo de datos sobre la infancia se lleva a cabo también el proyecto de controlar las contingencias y planificar incluso las deficiencias para conseguir un programa de gestión racional de las poblaciones".

Entiéndase esto: no estamos expresando una negación irritada frente a formas de control, evaluación o monitoreo informático de situaciones y prestaciones sociales. Solo indicamos que bien pueden implementarse sin la debida individualización del usuario aunque hasta ahora la historia no lo ha demostrado. Por el contrario, de acuerdo a Castel, en cita ut supra, lo que sí ha sido demostrado es el papel que le cupo a la infancia como segmento operativo para la gestión política de la pobreza y de la población. 
4. Podríamos hablar de ciertas inercias adultocéntricas en el sistema de protección a la infancia y la familia que oscilan entre la protección y la contención. Del mismo modo, si existe un pasaje de políticas sociales basadas en necesidades a otras basadas en un enfoque de derechos, vale la pena preguntarse si algo ha cambiado sustantivamente.

Más que un punto a desarrollar, nos permitimos en este ítem colocar ciertas reflexiones de cierta manera ordenadas.

Es evidente que nuestro país y la región, en general, atraviesa desde la época de las dictaduras cívico-militares una crisis de protección y cuidado respecto a la infancia y la adolescencia que, en la era de gobiernos progresista, se intenta superar (Giorgi, 2008): aunque Morás (1992) ubica la crisis del modelo de protección-control a mitad del siglo XX con sobradas razones, basta pensar en la crisis del propio Estado de bienestar. Tal crisis responde a una multiplicidad de factores que engloban desde las transformaciones socioculturales en las relaciones familiares $y$ de género, hasta antiguas concepciones políticas sobre el Estado social; desde nuevas formas y expresiones de la pobreza hasta procesos demográficos que agudizan de diversa manera problemas sociales, en el presente o a futuro, todo ello a modo de simples ejemplos.

Giorgi (2008: 12) vincula esta crisis a la construcción de la desesperanza, de la soledad y del desamparo e indica:

"Estos tres procesos son producidos por un conjunto de factores fuertemente correlacionados: deterioro de la autoestima y vivencia de impotencia ante la adversidad ("locus de control externo"); ausencia de futurización, deterioro de la solidaridad y sus redes; retracción e ineficacia del Estado de protección - vaciamiento y desmantelamiento de las instituciones y servicios históricamente encargados de la asistencia a los sectores más vulnerables".

Uno de los elementos para superar esta situación es la necesidad de un cambio en la mirada sobre la infancia y la adolescencia. De la infancia/adolescencia como amenaza o peligrosa, a una infancia/adolescencia como sujetos de derechos, es decir, como un bien social que debe ser, por tanto, protegido y cuidado, no solo por meros factores demográficos, que también pesan (Giorgi, 2008). Y para modificar esa mirada, el mundo adulto debe, de cierta manera, retirarse simbólicamente, para permitir que la mirada adultocéntrica dé paso a miradas sobre las infancias y adolescencias. Pero la mirada del mundo adulto debe concentrarse allí donde se encuentran sus responsabilidades: pensar las instituciones en función de los NNA y no de las necesidades adultas, superar la fragmentación y desencuentros del sistema de protección social en andamiento que, como ya dijimos, es mucho más complejo que el típico del Estado de bienestar.

Si el abandono fue y es construido punitivamente (Erosa; Iglesias, 2000), si la infancia trasmutada en minoridad se transformó en ese sujeto bicéfalo indiferenciado, por ser abandonada y delincuente (García Méndez, 1992:15), a partir de posturas defensivas, la protección a la infancia asumió históricamente la forma del control de la infracción básicamente (Leopold, 2008).

Hoy por hoy, son otras las infancias, las adolescencias y las instituciones que conforman la trama del sistema de protección social. Son otras las formas de ejercicio del poder, como ya dijimos. Pero aún quedan en el debe resabios de posturas resumidas en el párrafo anterior, donde infancia pobre y delito se transforman casi en sinónimos, en un clima y un gobierno de inseguridad social (Wacquant, 2010); donde también adolescencia pobre/adicciones/embarazos no deseados se transforman en una constelación de variables perfectamente correlacionadas; donde escuela pobre/violencia/infracción es también una suerte de ecuación.

Desde otra perspectiva cabe agregar como tendencia regional $-\mathrm{y}$ no estrictamente regional- el desplazamiento de políticas pensadas a partir de necesidades de grupos, individuos o clases a políticas cuyo horizonte y norte lo constituyen una serie de declaraciones de derechos. En el campo de la adolescencia y la infancia esto es algo fácilmente observable. La intencionalidad es clara: 
(...) para que el punto de partida no sea la existencia de personas con necesidades que deben ser asistidas, sino sujetos con derechos a demandar determinadas prestaciones y conductas (Abramovich, 2006:36).

Pero el pasaje de ser necesitado a ser sujeto de derechos que puede exigir o demandar no es lineal ni abrupto como la redefinición de los sustentos políticos de la ingeniería social. Si la ciudadanía plena es una deuda histórica para amplias mayorías de la población, este discurso basado en derechos encuentra sus límites en la propia historia latinoamericana, en sus formas de organización sociopolítica, y la propia realidad se encarga de reforzar el carácter de discurso del enfoque de derechos, más allá de muy buenas y sanas intenciones.

Esa construcción colectiva de derechos individuales e individualizados aún no se ha puesto en marcha en el campo de la infancia y la familia. Cabe agregar, además, que sería de cierto modo onírico pensar en tal concreción, pues toda emancipación humana supone la superación del dualismo entre el orden político y el orden social. Además, siguiendo el pensamiento de Marx (1998), la definición liberal de derechos podría entenderse del siguiente modo: la mayor dicha del todo se logra cuando cada uno procura su propia dicha individual. Cuando el particular se aísla hacia su particularidad pierde su sentido de universalidad, no se realiza de manera propia su modo social de ser, lo ideal y lo real marcha por caminos separados y se sitúan en planos distintos. Por ello la transformación necesaria es básicamente social y no política, ni puede ser realizada por actos políticos de sectores interesados aún en el bienestar de la infancia.

El tema, históricamente, ha sido siempre el mismo: cómo romper con esa mirada tan temerosa y defensiva sobre la infancia y la adolescencia minorizada. También otro tema ha sido siempre el mismo: dejar hablar a la infancia y no hablar en su nombre. Obviamente, existe otro más: si políticamente estamos, como sociedad, apostando a ello. Es decir, romper con la lógica penal que siempre estuvo presente en los espacios sociales de la infancia y la adolescencia pobre y habilitó la invisibilización de los problemas sociales. Romper con una lógica liberal de declaración de derechos hiperindividualizados. Si no encontramos respuestas a estas interrogantes históricas, poco más tendremos para decir, que sea útil y verdadero o, mejor dicho, verdadero y por su verdad, útil.

Pensar desde los bordes y los lugares más bajos de la escala social, donde se encuentran, en un doble proceso de regulación, las políticas sociales con aquellas netamente penales es un deber que como universitarios no debemos dejar sin elucidar. Pensar cómo dejar que infancia y adolescencia hablen y se hablen sin que sea un escándalo para el mundo adulto, al decir de Dolto (2004:13), es otro.

\section{Referencias}

ABRAMOVICH, V. (2006) Una aproximación al enfoque de derechos en las estrategias y políticas de desarrollo. Revista de La Cepal, $\mathrm{N}^{\circ}$ 88. Abril 2006.

ARIÉS, P. (1986) História Social da Criança e da Família. Rio de Janeiro: Graal.

ARIÑO, M. (2007) Familias tradicionales, nuevas familias, en TORRADO, S. (comp.). Población y Bienestar en la Argentina del primero al segundo Centenario; tomo II. Edhasa: Argentina.

BAQUERO, R.; NARODOWSKI, M. (1990) Normalidad y normatividad en pedagogía. En: Alternativas, Nro. 4. Pp. 35-46.

BAQUERO, R.; NARODOWSKI, M. (1994) ¿Existe la infancia? En: Revista del Instituto de Investigaciones en Ciencias de la Educación, Nro. 6. Pp. 61-66.

BARATTA, A.(1995) La niñez como arqueología del futuro. En: Bianchi, M. (comp..) El Derecho y los Chicos. Espacio: Argentina. Pp. 1322.

BARATTA, A. (1998) Infancia y Democracia. En: GARCÍA MÉNDEZ, E., BELOFF, M. (comps.), Infancia, ley y democracia en América Latina. Análisis crítico del panorama legislativo en el marco de la Convención Internacional sobre los Derechos del Niño (1990-1998), Temis/Depalma: Colombia. Pp. 21-40. 
BARRÁN, J. P. (1999) Historia de la sensibilidad en el Uruguay. Tomo I y II. EBO: Uruguay.

BAUMAN, Z. (2003) Comunidad. En busca de seguridad en un mundo hostil. Siglo XXI: España.

BECK, U.; GIDDENS, A.; LASH, S.(1997) Modernización Reflexiva. Política, tradición y estética en el orden social moderno. Alianza Editorial: España.

BECK, U. (1998) La sociedad del riesgo. Hacia una nueva modernidad. Paidós: Argentina.

BROWN, W. (2004) Human Rigths as the Politics of Fatalism. South Atlantic Quarterley, Vol. 103, Nro. 2/3. 2004..

BUCKINGHAM, D. (2002) Crecer en la era de los medios electrónicos. Tras la muerte de la infancia. Morata: España.

CASTEL, R. (1986) De la peligrosidad al riesgo. En: Materiales de Sociología Crítica. La Piqueta: España. Pp. 219-243.

COREA, C. Y LEWKOWICZ, I. (1999) ¿Se acabó la infancia? Ensayo sobre la destitución de la niñez. Lumen Humanitas: Argentina.

DE MARINIS, P. (1999) Gobierno, gubernamentalidad. Foucault y los anglofoucaultianos (O un ensayo sobre la racionalidad política del neoliberalismo) En: Ramos Torre, R.\& García Selgas, F. (ed.) Globalización, riesgo, reflexividad. Tres temas de la teoría social contemporánea. Centro de Investigaciones Sociológicas: España. Pp. 75 - 100.

DE MARTINO, M. (1998) Más allá de los derechos y políticas criminológicas: el sentido de la justicia. En: Red de Estudios sobre Instituciones Sociales y Prácticas Profesionales (comp.) La fragmentación de lo social: construcciones profesionales y campo sociojurídico en la región. Pp. 147 - 154. CIEJ FCS - DTS: Uruguay.

DE MAUSE, L. (1994) Historia de la infancia. $1^{\text {a }}$ ed. Alianza: España.

DOLTO. F. (2004) La causa de los niños. 2a Edición. Paidós: Argentina.

DONZELOT, J. (1986) A Polícia das Famílas. Graal: Brasil.
DOUGLAS, M.; (1990) Risk as Forensic Resource. Daelus, (119), 4, Pp 11-16.

EROSA, H; IGLESIAS, S. (2000) La construcción punitiva del abandono. CENFORES-INAME: Uruguay.

FOUCAULT, M. (1977) Historia de la Sexualidad I. La voluntad de Saber. México: Siglo XXI: México.

FOUCAULT, M. (1992a) A política de Saúde no Século XVIII. En: Microfísica do Poder. $\left(10^{\mathrm{a}}\right.$ Ediçao). Graal: Brasil. pp. 193 -207.

FOUCAULT, M. (1992b) A gubernamentalidade. En: Microfísica do Poder. $\left(10^{\mathrm{a}} \mathrm{Ed}\right) \mathrm{Graal}$ : Brasil. pp. 277 - 293.

FOUCAULT, M. (2001) El sujeto y el poder. En: Dreyfus, H. \& Ravinow, P. Michel Foucault: más allá del estructuralismo y la hermenéutica. Nueva Visión: Argentina. Pp. 241- 259.

FOUCAULT, M. (2006) Seguridad, Territorio y Población. Curso en el Collège de France (1977-1978) FCE: Argentina.

GARCÍA MÉNDEZ, E. (1992) Derecho de la Infancia-Adolescencia en América Latina: de la Situación Irregular a la Protección Integral. Forum Pacis: Colombia.

GARCÍA MÉNDEZ, E. (1997) Derecho de la Infancia-Adolescencia en América Latina: de la situación irregular a la protección integral. Forum Pacis: Colombia.

GARLAND, D. (1997) Governmentality and the problem of crim. Theoretical Criminology (1), 2, 173-214.

GÉLIS, J. (1992) La individualización del niño. En: Ariès, P. Historia de la vida privada: el proceso de cambio en la sociedad de los siglos XVI-XVIII. Taurus: España.

GEREMEK, B.(1986) La Piedad y la Horca. Historia de la miseria y de la caridad en Europa. Alianza: España.

GIORGI, V. (1998) Reflexiones sobre políticas de infancia. En: Red de Estudios sobre Instituciones Sociales y Prácticas Profesionales (comp.) La fragmentación de lo social: construcciones profesionales y campo socio-jurídico en la región. pp. 10 - 21. CIEJ - FCS - DTS: Uruguay. 
GORDON, C. (1999) Governmental rationality: an introduction, en: Burchell, G.; Gordon, C.; Miller, P. The Foucault Effect. Studies in Governmentality. The University of Chicago Press: USA. Pp. 1-51.

HELLER, A. (1994) Más allá de la justicia. Planeta Agostini: Argentina.

KRMPOTIC, C. (2009) En búsqueda de un nuevo patrón familiar (o las dificultades para aceptar el mestizaje). En: De Martino, M. (comp.). Infancia, Familia y Género. Múltiples problemáticas, múltiples abordajes. Ediciones Cruz del Sur: Uruguay. Pp. 201-214.

LAJOLO, M. (2009). Infância de papel e tinta, en de Freitas, M. (org). História Social da Infância no Brasil. 7ma. Ediçao. pp. 229 - 250. Cortez: Brasil.

LEMKE, T. (2001) "The Birth of bio-politics: Michel Foucault's lecture at the College de France on neo-liberal governmentality. En: Economy and Society (30), 2. pp. 190-207.

LEOPOLD, S. (1998) Campo socio-jurídico y construcciones profesionales: reflexiones desde el ámbito académico del Trabajo Social. En: Red de Estudios sobre Instituciones Sociales y Prácticas Profesionales (comp.) La fragmentación de lo social: construcciones profesionales y campo socio-jurídico en la región. pp. 99 - 107. CIEJ - FCS - DTS: Uruguay.

MARX, K. (1998) La cuestión judía. Need: Argentina.

MITJAVILA, M. (1999) O Risco e as estrategias de medicalizaçao do Espaço Social: Medicina Familar no Uruguay (1985. 1994) Tese apresentada à Faculdade de Filosofia, Letras e Ciencias Humanas da Universidade de São Paulo para obtençao do titulo de Doutor em Sociología. São Paulo.

MORÁS, L. E. (1992) Los Hijos del Estado. Fundación y crisis del modelo de proteccióncontrol de menores en Uruguya. Serpaj - FCS.: Uruguay.

MORÁS, L.E.(2009) ¿Una nueva cuestión social? Ensayo sobre las violencias y el deterioro de la convivencia en el Uruguay actual. En: De Martino, M. (comp.). Infancia, Familia y
Género. Múltiples problemáticas, múltiples abordajes. Ediciones Cruz del Sur: Uruguay. pp. 147-160.

MORENO, J. L. (2007) Las uniones consensuales: el desafío historiográfico de la ilegitimidad, en TORRADO, S. (comp.). Población y Bienestar en la Argentina del primero al segundo Centenario; tomo I. Edhasa: Argentina.

NARODOWSKI, M. (1994) Infancia y poder. La conformación de la pedagogía moderna. Aique: Argentina.

NARODOWSKI, M. (1999) Después de clase. Desencantos y desafíos de la escuela actual. Novedades Educativa: Argentina.

NARODOWSKI, M. (2004) El desorden de la educación. Ordenado alfabéticamente. Prometeo: Argentina.

O'MALLEY, P. (1991) Risk and responsibility. En: Barry, A.; Osborne, T.;Rose, N. (ed) Foucault and Political Reason. Chicago: The University of Chicago Press, 189-207.

O'MALLEY, P. (1996) Post-Keynesian Policing. Economy \& Society, (25), 2, 137-155.

POLLOCK, L. (1993) Los niños olvidados. Relaciones entre padres e hijos de 1500 a 1900. FCE: México.

POSTMAN, N. (1994) The disappearance of childhood. Vintage Books: USA.

RABELLO DE CASTRO, L. (org.) (1999) Infancia y adolescencia en la cultura del consumo. Lumen: Argentina.

RANCIÈRE, J. (2004) Who is the Subject of the Rigths of Man?. South Atlantic Quaterly, 103, 2/3, 297-310.

RODRÍGUEZ, I. Condicionantes teóricos en el surgimiento de la sociología de la infancia: el caso de la sociología española. México: Derechos de Infancia. 2000. http://www.derechosinfancia.org.mx/Temas/temas_sociologia1.htm. Recuperado el 17 de septiembre de 2009.

ROSE, N.; MILLER, P. (1992) Political Power beyond the State: problematics of government. Bristish Journal of Sociology, 43, 2, 173-205. 
STEINBERG, S.; KINCHELOE, J. (comps.) (2000); Cultura infantil y multinacionales. Morata: España.

VARELA, J.; ÁlVAREZ-URIA, F. (1991) Arqueología de la escuela. Madrid: La Piqueta.
WACQUANT, L. (2010) Castigar a los pobres. El gobierno neoliberal de la inseguridad social. Gedisa: España

ZIZEK, S. (2005) La suspensión política de la ética. Fondo de Cultura Económica: Argentina. 